\title{
Observations on the effects on rats of compounds related to acrylamide
}

\author{
J. M. BARNES \\ Medical Research Council Toxicology Unit, Carshalton, Surrey
}

\begin{abstract}
Barnes, J. M. (1970). Brit. J. industr. Med., 27, 147-149. Observations on the effects on rats of compounds related to acrylamide. Nine compounds (Table), close chemical relations of acrylamide, were given to adult rats both in their diet and as repeated daily doses by mouth. Dose rates were such that with acrylamide acute poisoning and neuropathy would have resulted. Seven of the compounds were without effect. $N$-methylacrylamide and $N$-hydroxymethylacrylamide produced some neurotoxic effects in large doses. The presence of acrylamide as an impurity in the compound tested was not excluded.
\end{abstract}

The observation that rats given repeated doses of acrylamide (I) developed a peripheral neuropathy (Fullerton and Barnes, 1966) explained the unusual toxic effects of this compound that had been reported earlier by others (McCollister, Oyen, and Rowe,

\section{TABLE}

Names AND Chemical Formulae of the Compounds TESTED

\begin{tabular}{|c|c|c|}
\hline I & Acrylamide & $\mathrm{CH}_{2}: \mathrm{CH} \cdot \mathrm{CO} \cdot \mathrm{NH}$, \\
\hline II & Sodium acrylate & $\mathrm{CH}_{2}: \mathrm{CH} \cdot \mathrm{CO}, \mathrm{Na}$ \\
\hline III & Acrylonitrile & $\mathrm{CH}_{2}: \mathrm{CH} \cdot \mathrm{CN}$ \\
\hline IV & $N$-methylacrylamide & $\mathrm{CH}_{2}: \mathrm{CH} \cdot \mathrm{CO} \cdot \mathrm{NHMe}$ \\
\hline $\mathbf{V}$ & $\begin{array}{l}N \text {-hydroxy- } \\
\text { methylacrylamide }\end{array}$ & $\mathrm{CH}_{2}: \mathrm{CH} \cdot \mathrm{CO} \cdot \mathrm{NH} \cdot \mathrm{CH}_{2} \cdot \mathrm{OH}$ \\
\hline VI & $N N$-diethylacrylamide & $\mathrm{CH}_{2}: \mathrm{CHC} \cdot \mathrm{O} \cdot \mathrm{NEt}_{2}$ \\
\hline VII & 2-methylacrylamide & $\mathrm{CH}_{2}: \mathrm{CMe} \mathrm{CO} \cdot \mathrm{NH}_{2}$ \\
\hline VIII & Crotonamide & $\mathrm{CH}_{2} \cdot \mathrm{CH}: \mathrm{CH} \cdot \mathrm{CO} \cdot \mathrm{NH}_{2}$ \\
\hline IX & Senecioic acid amide & $\mathrm{Me}_{2} \mathrm{C}: \mathrm{CH} \cdot \mathrm{CO} \mathrm{NH}_{3}$ \\
\hline $\mathbf{x}$ & Allyl acetamide & $\mathrm{CH}_{2}: \mathrm{CH} \cdot \mathrm{CH}_{2} \cdot \mathrm{CO} \cdot \mathrm{NH}_{2}$ \\
\hline
\end{tabular}

1964). Interest in these experimental findings was roused by the discovery of clinical peripheral neuropathy in men who were occupationally exposed to acrylamide under poor general hygienic conditions (Garland and Patterson, 1967).

In experiments (unpublished) carried out in 1963 in this laboratory, it was observed that $N$-hydroxymethylacrylamide (V), which was being used commercially, did not produce the same acute or chronic toxic effects on rats as acrylamide.

When the nature of the lesion produced by acrylamide had been established part of the initial studies of the mechanism involved included an examination of the effects of some closely related compounds. Because some of the compounds have an actual or potential industrial use, these findings are recorded and briefly discussed.

Fassett (1963) refers to unpublished work in his laboratory which showed that 2-methylacrylamide (VII) and $N N$-dimethylacrylamide were not toxic to cats and $N$-hydroxymethylacrylamide was much less toxic than acrylamide.

\section{Materials and methods}

Compounds I and III were purchased from British Drug Houses Ltd. and II was prepared from acrylic acid from the same source. Compound VII was purchased from Aldrich Chemical Co. Inc., and $V$ was a gift from 
Vinyl Products Ltd., Carshalton. Compounds IV, VI, VIII and IX were synthesized in these laboratories by Dr. A. R. Mattocks.

$N$-Methylacrylamide (IV) and $N, N$-diethylacrylamide (VI), prepared according to Koton, Sokolova, Savritskaya, and Kiseleva (1958), were colourless oils, $\mathrm{N}_{D^{23}} 1 \cdot 4723$ and 1.4666 respectively. Crotonamide (VIII) and senecioic acid amide (IX) were prepared from the acids by standard methods and had melting points of $162^{\circ}$ and $113^{\circ}$ respectively.

Young adult albino rats of the Porton strain were used. Single oral doses were given in aqueous solutions. For long-term feeding the powders were added to MRC diet $41 \mathrm{~B}$ in powder form and mixed with a Hobart mixer for 20 minutes.

The animals were weighed weekly and their gait and stance were observed when walking on a non-slippery surface including an ascent up a sloping wooden board. A good test for hind limb activity was to hold the rat by the tail in front of a sloping bar. When a normal rat grasps this with the front paws it then quickly finds it and grasps it with the hind feet. This reflex is lost early in peripheral neuropathies. The ability to maintain itself on a smooth bar is a measure of muscle strength and normal sensation in the paws.

\section{Results}

\section{Acrylamide}

Given as two doses of $100 \mathrm{mg} / \mathrm{kg}$ by mouth on successive days, this killed most rats within a few days, with signs of gross general weakness. Given in the diet at $400 \mathrm{ppm}$, signs of disability were evident within four weeks and were marked by eight weeks.

In the majority of the tests with the other compounds, a group of six male rats was given the compound in the diet at 400 ppm for 10 weeks and then at $800 \mathrm{ppm}$ for a further three weeks. At the end of this period a succession of oral doses was given to four of the six rats leaving two as untreated controls. The details for each compound follow:

\section{Sodium acrylate}

Ten weeks feeding at $400 \mathrm{ppm}$ was followed by three weeks at $800 \mathrm{ppm}$ and then four rats were given seven successive doses of $100 \mathrm{mg} / \mathrm{kg}$ over the next nine days. There were no adverse effects.

\section{Acrylonitrile}

Six rats were given 15 successive doses of $30 \mathrm{mg} / \mathrm{kg}$ followed by seven doses of $50 \mathrm{mg} / \mathrm{kg}$ and then 13 doses of $75 \mathrm{mg} / \mathrm{kg}$ over a period of seven weeks. There were no adverse effects.

\section{IV $N$-methylacrylamide}

Ten weeks feeding at $\mathbf{4 0 0} \mathrm{ppm}$ was followed by three weeks at $800 \mathrm{ppm}$. During the next two weeks four rats received seven doses of $100 \mathrm{mg} / \mathrm{kg}$. One rat became very weak and was killed. The remaining three received 10 further doses of $50 \mathrm{mg} / \mathrm{kg}$ without deterioration followed by a further 11 doses of 100 $\mathrm{mg} / \mathrm{kg}$ during the next three weeks. At the end of this period two of the three had definite weakness like mild acrylamide poisoning.

\section{V $N$-hydroxymethylacrylamide}

Experiment 1 Six male rats received seven doses of $100 \mathrm{mg} / \mathrm{kg}$ in 12 days, and on day 23 and 24 a dose of $200 \mathrm{mg} / \mathrm{kg}$. They showed fine tremors and were generally affected but did not develop the gross clinical picture of weakness. Killed on day 37 none showed the typical bladder changes from chronic urinary retention seen in many rats poisoned with acrylamide.

Experiment 2 Six male rats fed a diet containing $400 \mathrm{ppm}$ for 14 weeks followed by seven weeks at $800 \mathrm{ppm}$ and then six weeks at $1600 \mathrm{ppm}$. At the end of this 27-week period of feeding the rats all had definite weakness which recovered somewhat during the three months following their return to a normal diet. These findings are discussed below.

\section{VI $N N$-diethylacrylamide}

Six male rats were fed a diet containing $400 \mathrm{ppm}$ for 10 weeks followed by three weeks at $800 \mathrm{ppm}$ and during the next two weeks seven doses of $100 \mathrm{mg} / \mathrm{kg}$. There were no adverse effects.

\section{2-Methylacrylamide}

Six male rats were given 10 successive doses of 50 $\mathrm{mg} / \mathrm{kg}$ over 11 days followed by 10 doses of 100 $\mathrm{mg} / \mathrm{kg}$ over the next 14 days. There were no adverse effects.

\section{Crotonamide}

Six male rats were fed a diet containing $400 \mathrm{ppm}$ for nine weeks followed by $800 \mathrm{ppm}$ for the next five weeks. Four of the rats then received seven doses of $100 \mathrm{mg} / \mathrm{kg}$ over the next nine days. There were no adverse effects.

\section{Senecioic acid amide}

Six male rats were fed a diet containing $400 \mathrm{ppm}$ for 10 weeks followed by 800 ppm for three weeks and then four of the rats were given seven doses of 100 $\mathrm{mg} / \mathrm{kg}$ during the next nine days. There were no adverse effects.

X Allylacetamide (pent-4:5-enoic acid amide)

Six female rats were given seven doses of $100 \mathrm{mg} / \mathrm{kg}$ over eight days followed by 10 doses of $200 \mathrm{mg} / \mathrm{kg}$ over the next 14 days. There were no adverse effects.

\section{Discussion}

These experiments indicate that among a series of closely related compounds acrylamide is unique in 
its ability to produce acute and chronic toxic effects in rats associated with injury to the nervous system. In the experiments described above, $N$-hydroxymethylacrylamide from a commercial source was used and appeared to have a very weak activity compared to that of acrylamide. In later work on the mechanism of action of acrylamide, Hashimoto and Aldridge (1970) made further studies with $\mathrm{N}$-hydroxymethylacrylamide but, as a first step, purified the commercial product which was found to contain some acrylamide. Difficulties of separation made it impossible to determine the exact degree of contamination, but it was undoubtedly quite low. However, Hashimoto and Aldridge (1970) went on to show that rats which were exposed to pure $N$-hydroxymethylacrylamide in doses that did not produce evidence of neurological damage were more sensitive to the neurotoxic effects of acrylamide. It is probable, therefore, that the neurotoxic effects of the very large doses of commercial $N$-hydroxymethylacrylamide used in these experiments was due to the presence of acrylamide. $N$-methylacrylamide also had some slight effect in large doses.The purity of this compound was not checked. It is unlikely that $N$-demethylation occurs since the intermediate product would be $N$-hydroxymethylacrylamide which is not neurotoxic.

I am grateful to Dr. A. R. Mattocks for his help in selecting and providing some of the compounds tested; to Mr. W. P. J. Baily, Vinyl Products Limited, Carshalton for information about and supplies of $N$-hydroxymethylacrylamide and to Mr. C. R. Kennedy for technical assistance.

\section{References}

Fassett, D. W. (1962). Organic acids, anhydrides, lactones, acid halides and amides, thio acids. Chapter 40 in Industrial Hygiene and Toxicology. 2nd ed., Vol. 2, Ed. Patty, .F. A., Interscience Publishers, New York.

Fullerton, Pamela M., and Barnes, J. M. (1966). Peripheral neuropathy in rats produced by acrylamide. Brit. J. industr. Med., 23, 210-221.

Garland, T. O., and Patterson, M. W. H. (1967). Six cases of acrylamide poisoning. Brit. med. J., 4, 134-138.

Hashimoto, K., and Aldridge, W. N. (1970). Biochemical studies on acrylamide, a neurotoxic agent. Biochem. Pharmacol., in press.

Koton, M. M., Sokolova, T. A., Savitskaya, M. N., and Kiseleva, T. M. (1958). Synthesis of $N$-substituted methacrylamides. Chem. Abstr., 52, 6228f.

McCollister, D. D., Oyen, F., and Rowe, V. K. (1964). Toxicology of acrylamide. Toxicol. appl. Pharmacol., 6, 172-181.

Received for publication November 21, 1969. 